\title{
UCRL-TR-217775
}

LAW RENCE LIVERMORE N A T IO N A L LABORATORY

Simulations of the 1906 San Francisco Earthquake

A. Rodgers, A. Petersson, H. Tkalcic

December 16, 2005 
This document was prepared as an account of work sponsored by an agency of the United States Government. Neither the United States Government nor the University of California nor any of their employees, makes any warranty, express or implied, or assumes any legal liability or responsibility for the accuracy, completeness, or usefulness of any information, apparatus, product, or process disclosed, or represents that its use would not infringe privately owned rights. Reference herein to any specific commercial product, process, or service by trade name, trademark, manufacturer, or otherwise, does not necessarily constitute or imply its endorsement, recommendation, or favoring by the United States Government or the University of California. The views and opinions of authors expressed herein do not necessarily state or reflect those of the United States Government or the University of California, and shall not be used for advertising or product endorsement purposes.

This work was performed under the auspices of the U.S. Department of Energy by University of California, Lawrence Livermore National Laboratory under Contract W-7405-Eng-48. 


\author{
Simulations of the 1906 San Francisco Earthquake \\ Arthur Rodgers ${ }^{1}$, Anders Petersson ${ }^{2}$ and Hrvoje Tkalcic ${ }^{1}$ \\ ${ }^{1}$ Seismology Group, Atmospheric, Earth and Energy Department \\ ${ }^{2}$ Center for Applied Scientific Computing \\ Lawrence Livermore National Laboratory \\ Livermore, CA 94551
}

\title{
Summary
}

Simulations of the Great 1906 San Francisco earthquake are being performed as part of the event's centenary. LLNL is participating in a large effort to study this event and possible consequences if the event were to happen today. This document is meant to describe our efforts to others participating in the project. 


\section{Regional Simulations of the 1906 San Francisco Earthquake}

Arthur Rodgers and Anders Petersson (LLNL)

Bandwidth: $0-1.0 \mathrm{~Hz}$

Dimensions: extent of either detailed or regional USGS cencalvm model

Discretization: $\sim 25-250 \mathrm{~m}$

Features: 3D velocity model(s)

Minimum Vs: $300 \mathrm{~m} / \mathrm{s}$

A new elastic finite difference code is being developed at LLNL. We are using this code for two broad thrusts: 1) simulate the 1906 earthquake and 2) to simulate the moderate earthquakes within the regional ("detailed") model. The code works on a Cartesian geometry and can read in the USGS Bay Area Velocity Model (Release 05.1.0) in parallel using the software developed by Brad Aagaard. This allows a very nice flexibility to build a model on any desired computational domain or grid size.

We have used of the code simulate the 1906 earthquake. The map below shows a snapshot of the ground motion (curl of the velocity at the surface) shortly after initiation.

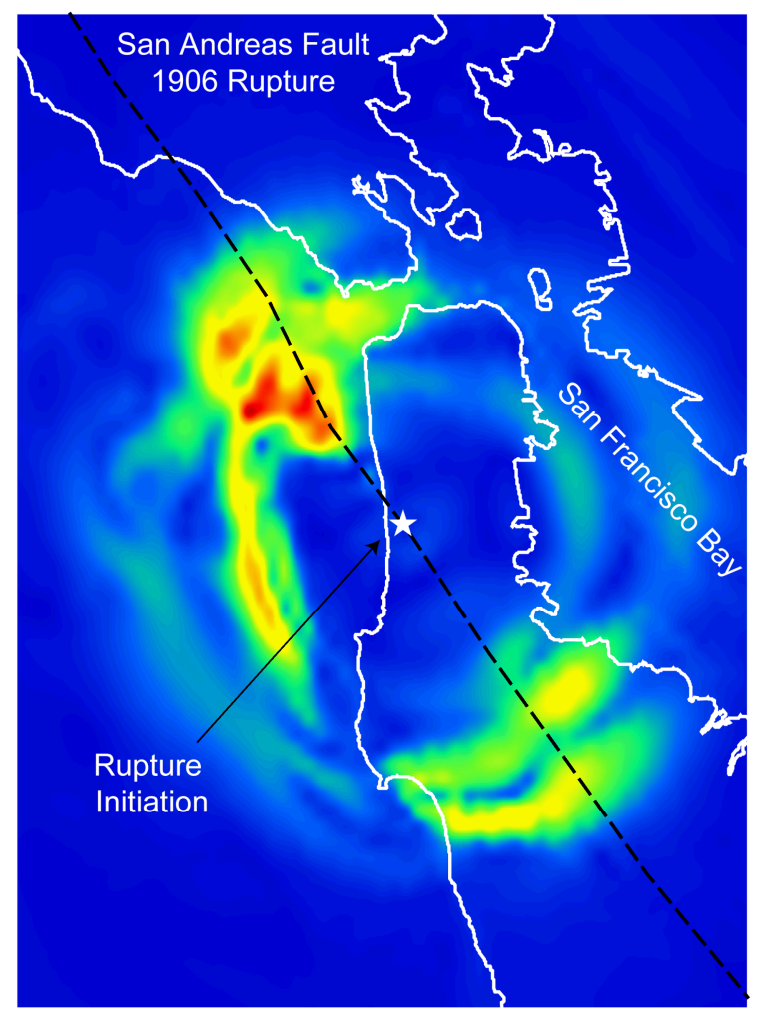

Simulations of moderate earthquakes will provide some tests of the model and identify elements and/or regions of the model that may be improved. The map below shows three events we have modeled along with broadband stations operated by the University of California, Berkeley. The three-component synthetics are compared to observed waveforms for the Gilroy event to station BRK (University of California, Berkeley) and 
station POTR (Potrero Hills, Fairfield). The data and synthetic waveforms are filtered $0.02-0.2 \mathrm{~Hz}$ (periods 5-50 seconds).

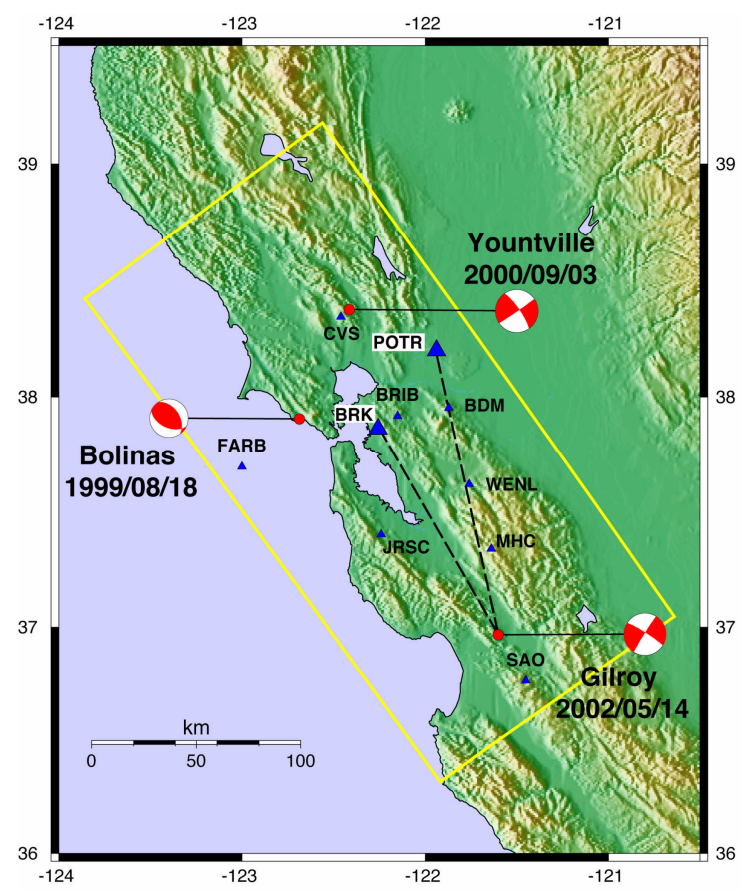

\section{Gilroy-BKS}

Gilroy-POTR

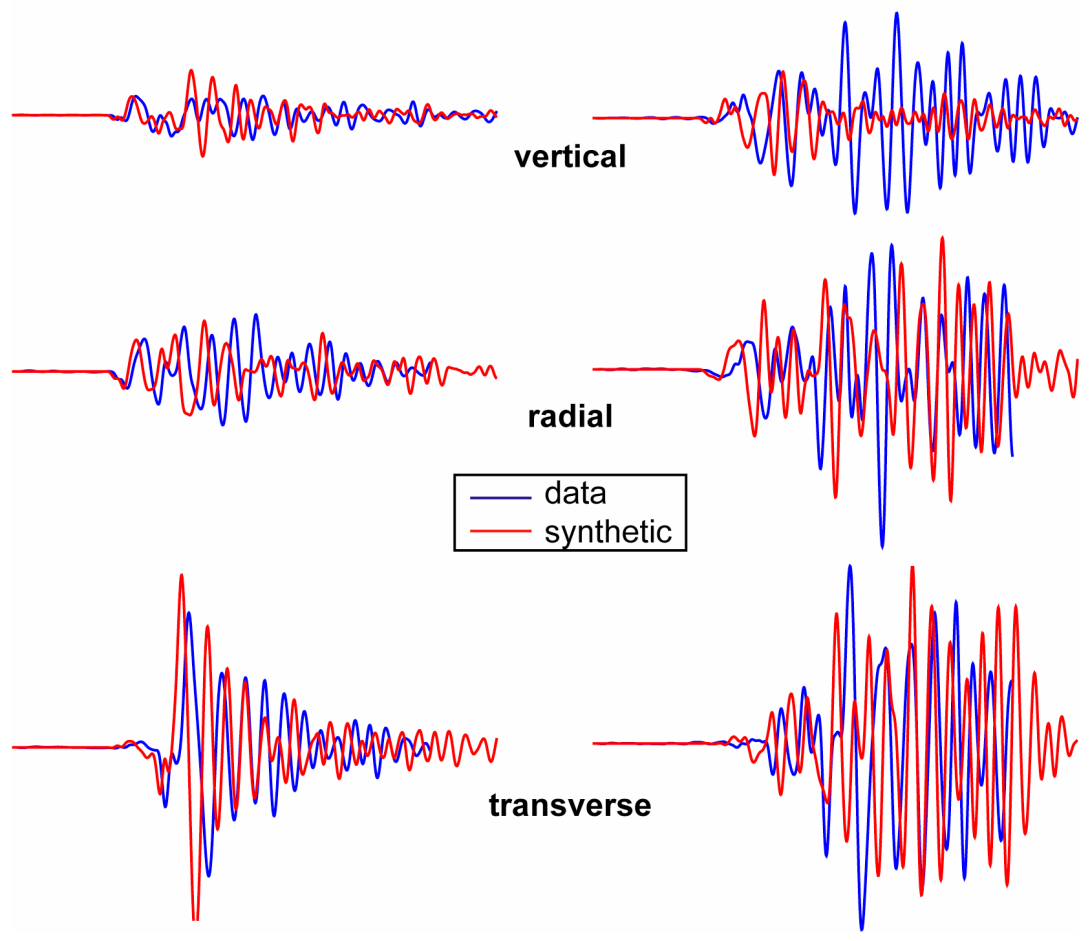




\title{
Global Simulations of the 1906 San Francisco Earthquake
}

\author{
Arthur Rodgers and Hrvoje Tkalcic (LLNL)
}

Bandwidth: $0-0.1 \mathrm{~Hz}$

Dimensions: globe or continental-scale section of the globe

Discretization: $\sim 5 \mathrm{~km}$

Features: 3D velocity model(s), topography, attenuation, spherical geometry

Minimum Vs: $2.0 \mathrm{~km} / \mathrm{s}$

We are using the Spectral Element Method (SEM) to provide a global perspective of the earthquake. We are simulating the available teleseismic waveforms from the event using a three rupture models (uniform; Wald et al., (1992); and Song et al., (2005)). These simulations are performed with the SPECFEM3D code developed by Komatitsch and Tromp (2002) and run on LLNL parallel computers. So far we have run the code on the MCR cluster. The simulations are quite demanding using over 1000 CPU's for up to 30 hours to capture the shear body-waves at distances up to $90^{\circ}$.

The global simulations are valid to $0.1 \mathrm{~Hz}$. This is appropriate to model the limited bandwidth of the 1906 data $(0.025-0.1 \mathrm{~Hz})$. We will also attempt simulations on a limited solid angle of the earth for a continental-scale perspective. Preliminary analysis shows only slight differences in the teleseismic S-waves between 1D (PREM) and 3D (S20RTS+CRUST2.0) models, while surface waves show dramatic differences. There are surface wave observations at a few stations (ALB, PTR, UPP, KOB, GOT, MUN. $\mathrm{ZIK})$. We are hopeful that modeling the surface waves with an accurate 3D model may be used to provide some insight into the rupture kinematics.

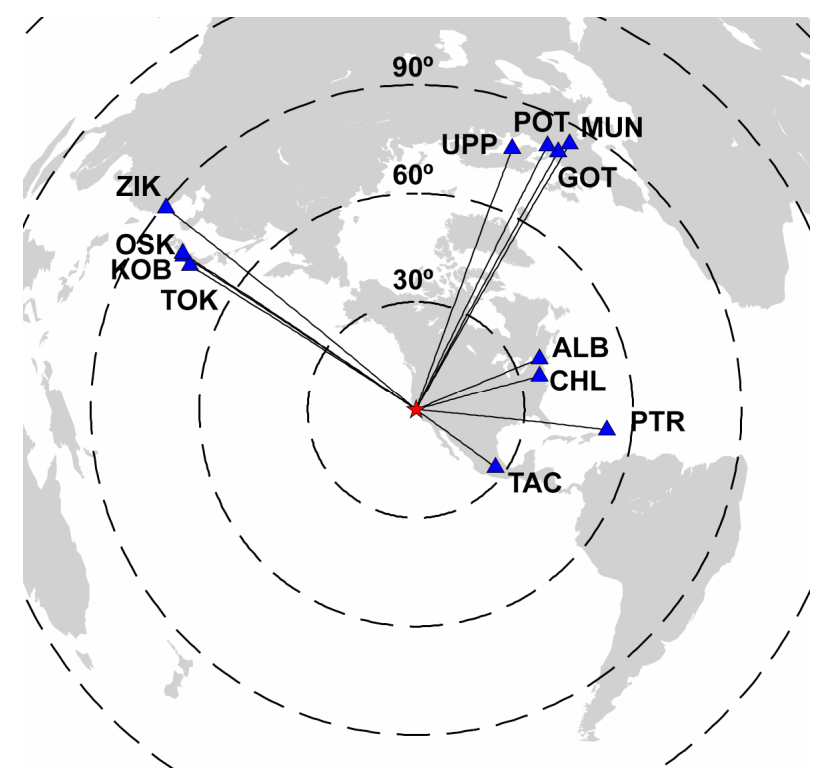

Map of the twelve (12) seismic stations that recorded the 1906 San Francisco earthquake. 
